\title{
High Strength Fiber Reinforced Concrete with Local Materials
}

\author{
Abdelkader Ammeri, Mondher Neifar \\ College of Engineering in Al-Qunfudhah \\ Umm Al-Qura University \\ Al-Qunfudhah, Kingdom of Saudi Arabia
}

\begin{abstract}
A study of the effect of silica fume rate on the mechanical properties of a high-strength concrete made with local materials was conducted in the laboratories of the engineering school of the author. The possible improvement of mechanical properties of high-strength concrete with steel fibers was also investigated. 2.5 tons of concrete were made to prepare 48 cylindrical specimens for the split tensile tests and 48 cubic specimens for compression tests. The study shows a significant effect of increasing the compressive strength with silica fume rates between $10 \%$ and $15 \%$. However, the effect on the tensile strength was very low. The steel fibers substantially increase the tensile strength without remarkable effect on the compression. These results prove the interest of coupling silica fume with steel fibers.
\end{abstract}

Keywords-High strength concrete; Local materials; Silica fume; Steel fiber

\section{INTRODUCTION}

With the intense development of the construction industry in Kingdom of Saudi Arabia, and the transition to the construction of internationally renowned works, ordinary concrete, basic component of these work, becomes a handicap to competitiveness and production of high structure quality. The high performance concrete in general and in particular the

high strength concrete began to take the field and has partially replaced the ordinary concrete in many developed countries. Based on this concern, we thought as future engineers to develop a high-strength concrete by local materials used in our city.

Passing from ordinary concrete to high strength concrete was made through addition of fines of different natures. The most used additions are silica fume [1], flying ash [2], and more recently the nano silica fume. [3] Others have done the coupling between silica fume and flying ash [4] and silica fume and nano silica fume [2]. Improving the strength by the addition of silica fumes is one point of agreement among most authors. However, there are disagreements about the optimum addition rate.

Several types of fiber have also been used to improve the strength of the concrete such as, glass fiber [5], the steel fibers [6] and the polypropylene fibers [7].

Certainly, the passage from an ordinary concrete to a high strength concrete requires the addition of fines, which increase the density of the concrete by filling the micropores and also improve the bonding cement - aggregates through a chemical process. Silica fume which is characterized by its size 100 times smaller than the grains of cement has been added to concrete at different rates. In addition of silica fume, steel fibers were also added at various proportions to optionally improve the mechanical characteristics of the concrete.

\section{MATERIALS}

\section{A. Aggregates}

1) Gravel

Two crushed gravel type G1 and G2 were used (Fig.1). Dosing gravel was set at $0.8 \mathrm{~m}^{3} / \mathrm{m}^{3}$ of concrete. Both gravel were used in equal parts.

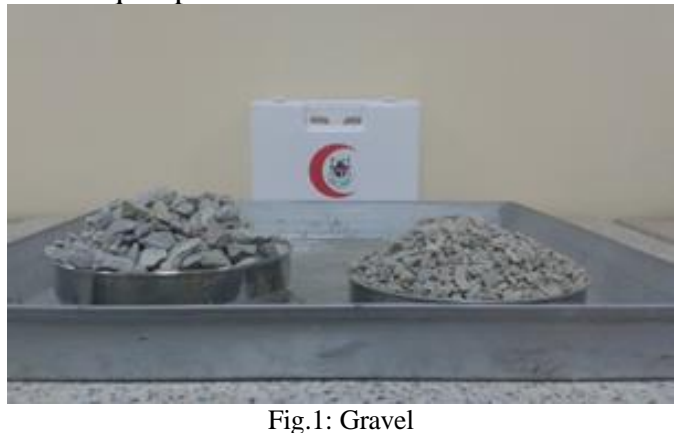

2) Sand

The sand used is locally sourced (Fig.2). The sand mix is set at $0.4 \mathrm{~m}^{3} / \mathrm{m}^{3}$ of concrete

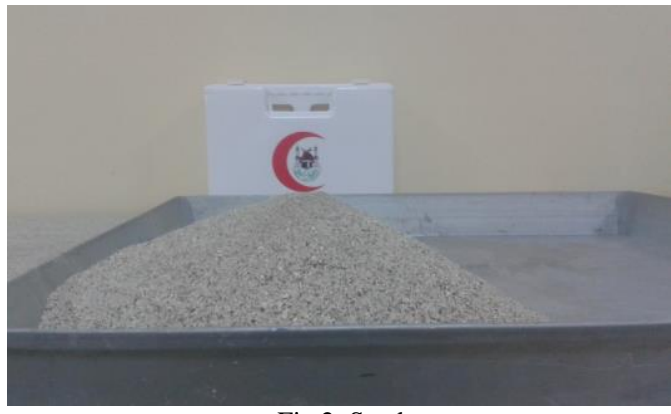

\section{3) Granulometry}

Fig.2: Sand

Sieve analysis test conducted according to ASTM C136 / $\mathrm{C} 136 \mathrm{M}$ was performed on the three aggregates. The particle size distribution curves of the three aggregates are shown in Fig.3. 


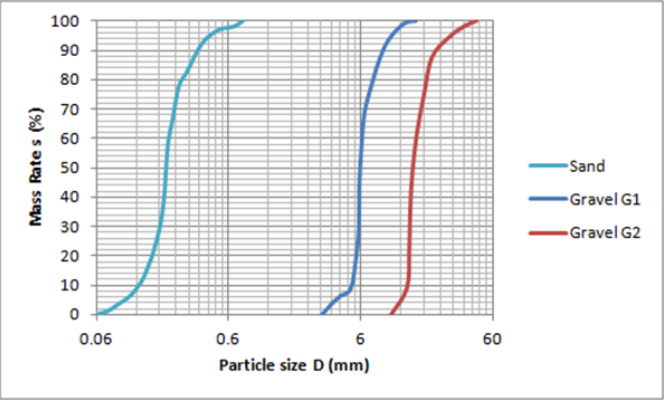

Fig.3: Particle size distribution curves

\section{B. Cement and silica fume}

The cement used is an ordinary Portland cement of class I 52.5N (SASO 1979/143) (Fig.5).

The silica fume used to densify the concrete has a size 100 times smaller than the cement (Fig.5).

The cement content + silica fume is set at $500 \mathrm{~kg} / \mathrm{m}^{3}$. Studied silica fume rates are: $0 \%, 5 \%, 10 \%$ and $15 \%$.

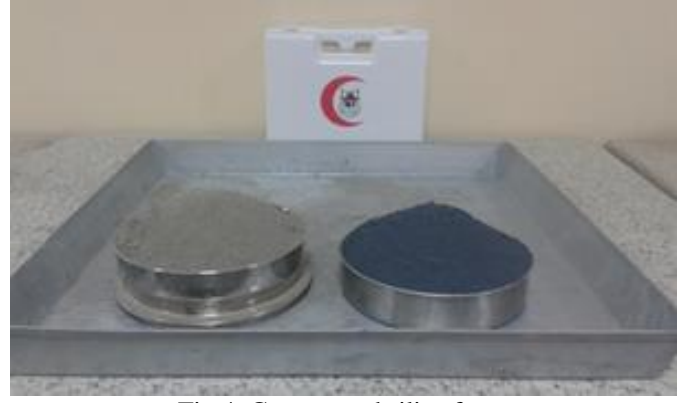

Fig.4: Cement and silica fume

\section{Superplasticizer}

Certainly, water is required for hydration of the cement, but the ratio of water (W) / cement (C) is inversely proportional to the compressive strength. Hence there is a need to reduce the quantity of water in order to achieve high resistance. This decrease is systematically followed by the decrease of the workability of concrete. To remedy this loss of workability a superplasticizer was added (Fig.5).

The amount of the superplasticizer to be added to the concrete is generally calculated as a proportion of the amount of cement + silica fume. To determine the optimal amount of superplasticizer, the slump was fixed to $9 \mathrm{~cm}$. This value is the average between $7 \mathrm{~cm}$ and $12 \mathrm{~cm}$ which ensures good workability of the concrete. Different percentage were tested (Fig.6) and the curve of the slumps according to the amount of the superplasticizer was plotted (Fig.7). It should be noted that the introduction of the silica fume increases the hydration water consumption, therefore the amount the superplasticizer is deduced from the curves of figure 8 for each percentage of silica fume.

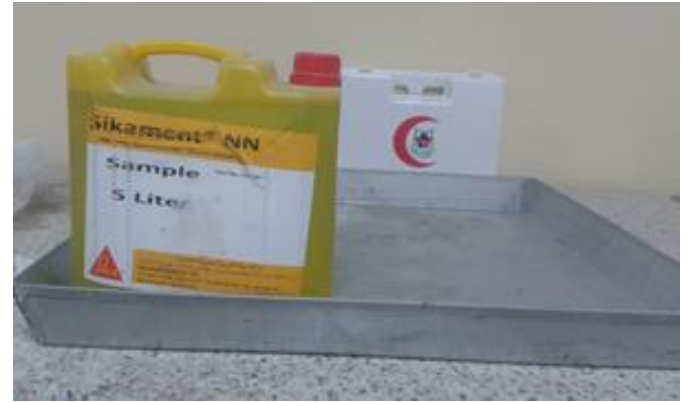

Fig.5: Superplasticizer
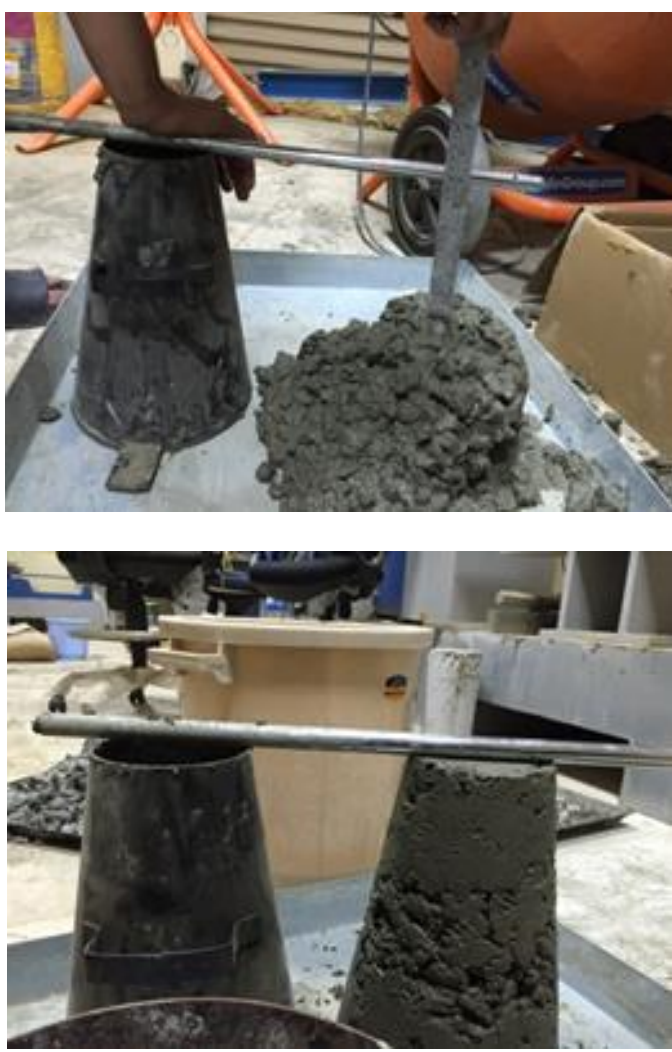

Fig.6: Slump test

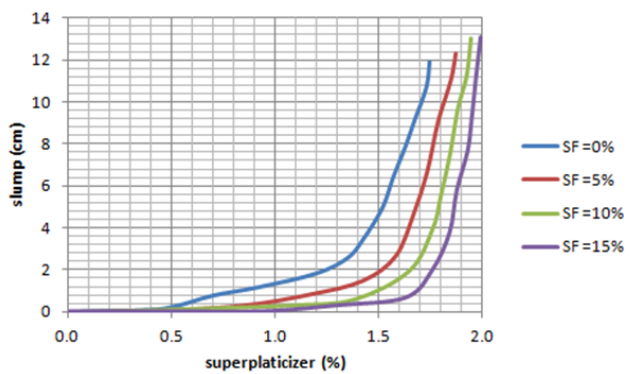

Fig.7: the slump versus le superplasticizer for different rates of silica fume

\section{Steel fiber}

The steel fibers used to improve the mechanical performance of the concrete had a ratio of $\mathrm{D} / \mathrm{L}=10 \%$. Indeed the steel diameter $\mathrm{D}=5 \mathrm{~mm}$ and the length $\mathrm{L}=50 \mathrm{~mm}$ (Fig. 8). The rates tested were $0 \%, 0.4 \%, 0.8 \%$ and $1.2 \%$ of the total volume of the concrete.

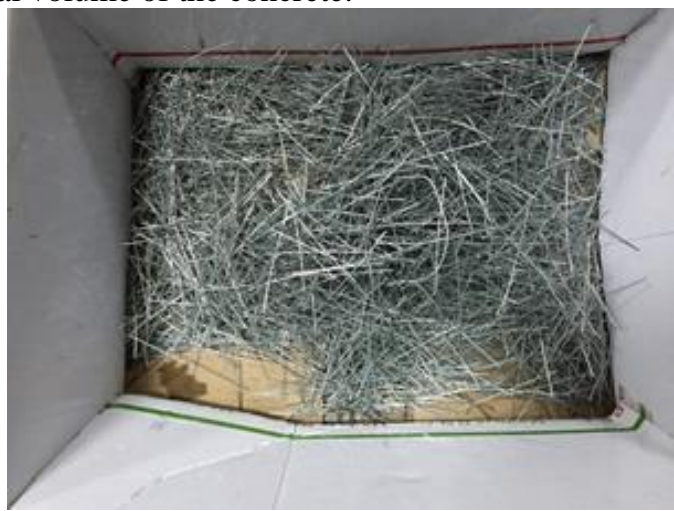

Fig.8: Steel fiber 


\section{EXPERIMENTAL PROGRAM}

\begin{tabular}{|c|c|c|c|c|c|c|c|c|}
\hline & \multicolumn{4}{|c|}{ TABLE I. } & \multicolumn{4}{|c|}{ ERIMENTAL PROGRAM } \\
\hline & \multicolumn{2}{|c|}{ steel fiber } & \multicolumn{2}{|c|}{ silica fume } & \multirow[b]{2}{*}{$\begin{array}{c}\text { cement } \\
(\mathrm{kg})\end{array}$} & \multirow[b]{2}{*}{$\begin{array}{l}\text { sand } \\
(\mathrm{kg})\end{array}$} & \multirow[b]{2}{*}{$\begin{array}{c}\text { gravel } \\
(\mathrm{kg})\end{array}$} & \multirow[b]{2}{*}{ water $(\mathrm{kg})$} \\
\hline & rate (\%) & weight (g) & $\begin{array}{c}\text { Rate } \\
(\%)\end{array}$ & $\begin{array}{c}\text { weight } \\
(\mathrm{g})\end{array}$ & & & & \\
\hline 531 & $0.0 \%$ & 0 & $0 \%$ & 0 & 31.235 & 41.230 & 82.461 & 12.494 \\
\hline 547 & $0.0 \%$ & 0 & $5 \%$ & 1562 & 29.673 & 41.230 & 82.461 & 12.494 \\
\hline 562 & $0.0 \%$ & 0 & $10 \%$ & 3124 & 28.112 & 41.230 & 82.461 & 12.494 \\
\hline 593 & $0.0 \%$ & 0 & $15 \%$ & 4685 & 26.550 & 41.230 & 82.461 & 12.494 \\
\hline 531 & $0.4 \%$ & 1949 & $0 \%$ & 0 & 31.235 & 41.230 & 82.461 & 12.494 \\
\hline 547 & $0.4 \%$ & 1949 & $5 \%$ & 1562 & 29.673 & 41.230 & 2.461 & 12.494 \\
\hline 562 & $0.4 \%$ & 1949 & $10 \%$ & 3124 & 28.112 & 41.230 & 82.461 & 12.494 \\
\hline 593 & $0.4 \%$ & 1949 & $15 \%$ & 4685 & 26.550 & 41.230 & 82.461 & 12.494 \\
\hline 531 & $0.8 \%$ & 3898 & $0 \%$ & 0 & 31.235 & 41.230 & 82.461 & 12.494 \\
\hline 547 & $0.8 \%$ & 3898 & $5 \%$ & 1562 & 29.673 & 41.230 & 82.461 & 12.494 \\
\hline 562 & $0.8 \%$ & 3898 & $10 \%$ & 3124 & 28.112 & 41.230 & 82.461 & 12.494 \\
\hline 593 & $0.8 \%$ & 3898 & $15 \%$ & 4685 & 26.550 & 41.230 & 82.461 & 12.494 \\
\hline 531 & $1.2 \%$ & 5847 & $0 \%$ & 0 & 31.235 & 41.230 & 82.461 & 12.494 \\
\hline 547 & $1.2 \%$ & 5847 & $5 \%$ & 1562 & 29.673 & 41.230 & 82.461 & 12.494 \\
\hline 562 & $1.2 \%$ & 5847 & $10 \%$ & 3124 & 28.112 & 41.230 & 82.461 & 12.494 \\
\hline 593 & $1.2 \%$ & 5847 & $15 \%$ & 4685 & 26.550 & 41.230 & 82.461 & 12.494 \\
\hline
\end{tabular}

The experimental program consists in carrying out of 16 different compositions. Of each mixture was prepared 3 cubic specimens of dimensions $15 \mathrm{~cm} \times 15 \mathrm{~cm} \times 15 \mathrm{~cm}$ and 3 cylindrical specimens of $15 \mathrm{~cm}$ diameter and $30 \mathrm{~cm}$ height (Fig.9). The cubic specimens are intended to determine the compressive strength at 28 days. Cylindrical test pieces for the split tensile tests at 28 days. Each measured value is the average of 3 measurements.

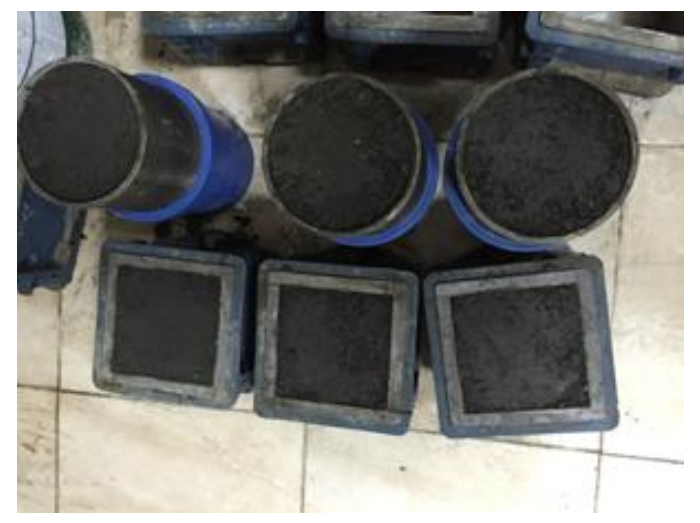

Fig.9: test specimens for compression and splitting

The specimens prepared were extracted after 24 hours from the molds (Fig.10) and immersed in water up to 28 days (Fig.11).

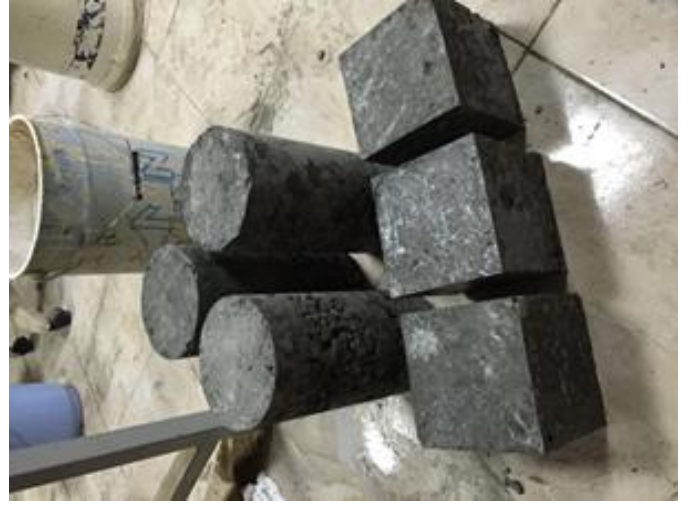

Fig.10: specimens after 24 hours

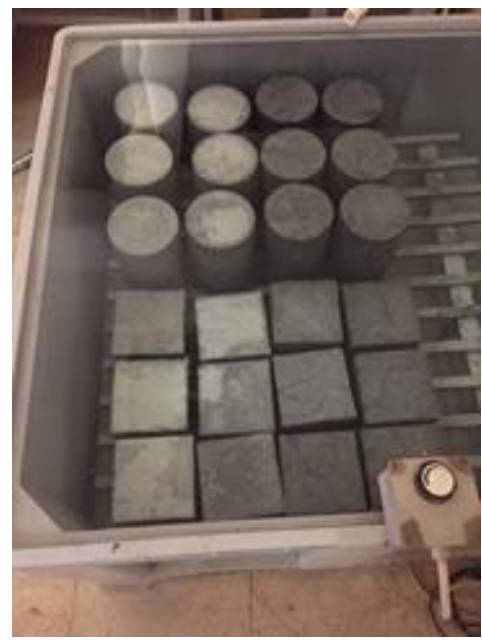

Fig.11: curing of the specimens

After 28 days the test pieces are recovered, dried in open air and then crushed in the compression machine (Fig.12Fig.13).

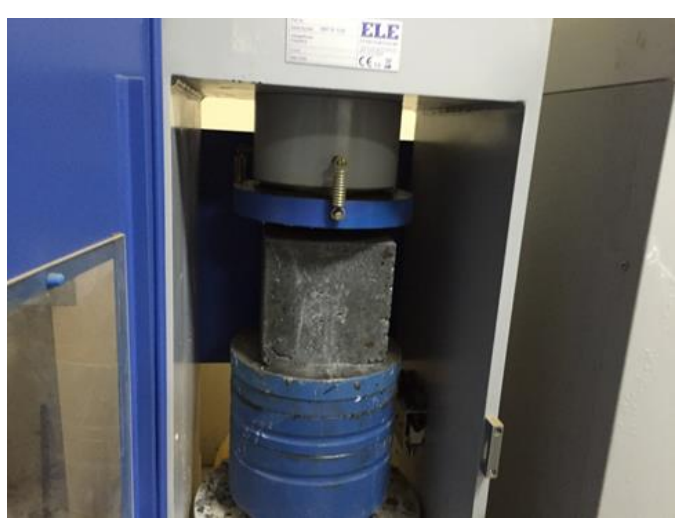

Fig.12: Compression test 


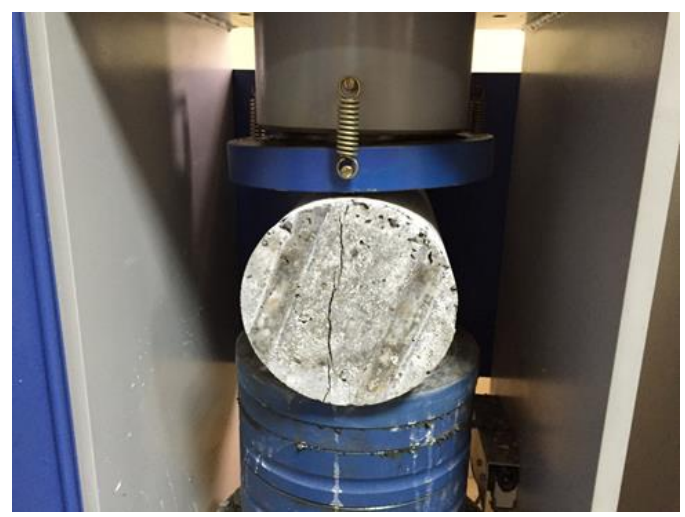

Fig.13: Split tensile test

\section{RESULTS AND DISCUSSIONS}

The curves of Fig.14 show the significant increase in compressive strength with the silica fume rate. Indeed the increase of more than $40 \%$ was recorded. However the contribution of steel fibers for compressive strength seems negligible.

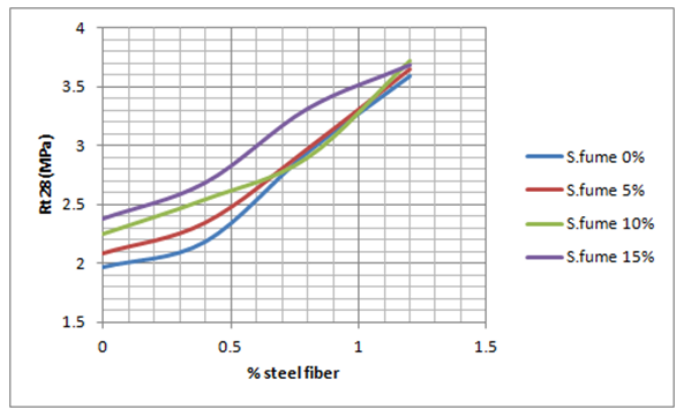

Fig.14: Compression test results

The curves in Fig.15 show the significant increase in tensile strength with the steel fibers rate. Indeed, this is an increase of more than $50 \%$. However the contribution of silica fume on tensile strength seems negligible.

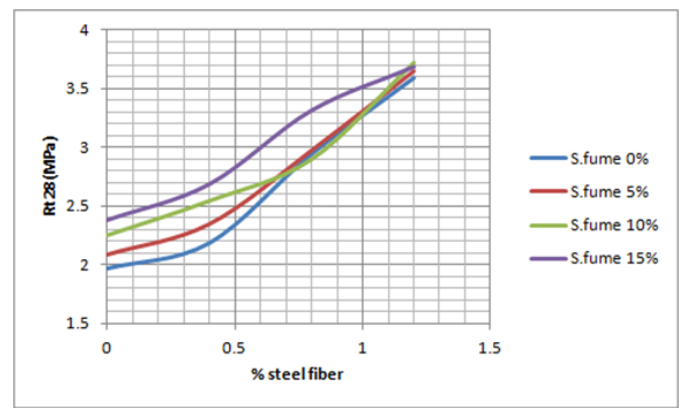

Fig.15: Split tensile test results
From these results it shows the interest of the silica fume coupling with the steel fibers.

\section{CONCLUSIONS}

During this study more than 2.5 tons of concrete were made. 96 specimens were prepared to study the contribution of silica fume and steel fibers in a concrete made with local materials. Was successfully make a gain of more than $40 \%$ of the compressive strength and a gain of more than $50 \%$ of the tensile strength through a composite: ordinary concrete + silica fume +steel fiber.

\section{REFERENCES}

[1] Mullera A.C.A., Scrivenera K.L., Skibstedb J., Gajewiczc A.M. McDonaldc P.J. Influence of silica fume on the microstructure of cement pastes: New insights from 1H NMR relaxometry. Cement and Concrete Research. Volume 74, August 2015, Pages 116-125.

[2] Gum S. R., Young B. L., Kyung T. K., Young S. C. The mechanical properties of fly ash-based geopolymer concrete with alkaline activators. Construction and Building Materials. Volume 47, October 2013, Pages 409-418.

[3] Mostafa J., Alireza P., Omid F. H., Davoud J. Comparative study on effects of Class F fly ash, nano silica and silica fume on properties of high performance self compacting concrete. Construction and Building Materials. Volume 94, 30 September 2015, Pages 90-104.

[4] Fereshteh A. S., Nicolas A. L., Mohammad S. Mechanical and durability properties of self consolidating high performance concrete incorporating natural zeolite, silica fume and fly ash. Construction and Building Materials. Volume 44, July 2013, Pages 175-181.

[5] Mastalia M., Dalvandb A., Sattarifardc A.R. The impact resistance and mechanical properties of reinforced self-compacting concrete with recycled glass fibre reinforced polymers. Journal of Cleaner Production Available online 11 March 2016, In Press.

[6] Deluce, J. R., Vecchio, F. J. Cracking Behavior of Steel FiberReinforced Concrete Members Containing Conventional Reinforcement. ACI Structural Journal 110.3 (May/Jun 2013): 481490

[7] Peng Z., Qing-fu L. Effect of polypropylene fiber on durability of concrete composite containing fly ash and silica fume. Composites Part B: Engineering. Volume 45, Issue 1, February 2013, Pages 1587-1594.

[8] Sallam, H.E.M. and Ibrahim, K.I.M. The compressive strength of fiber reinforced concrete (FRC) at high elevated temperatures. International Journal of Civil Engineering and Technology, 6(8), 2015, pp 53-60

[9] Ammeri, A., Neifar, M. and Ibrahim, K. Experimental and Numerica Study of the Split Tensile Test on a Silty Soil : Discrete Element Analysis. International Journal of Engineering Research \& Technology (IJERT), 5(01), January-2016, pp 929-936.

[10] ASTM C136 / C136M 